\title{
A study on uterine and vaginal arteries and their clinical significance
}

\author{
Nataraj KM', Pavan P Havaldar², Sameen $\operatorname{Taz}^{3}$, Shaik Hussain Saheb ${ }^{4}$ \\ ${ }^{1}$ Dr. Nataraj KM, Associate Professor of Surgery, JJM Medical College, Davangere, Karnataka, India, ${ }^{2}$ Dr. Pavan P Havaldar, \\ Associate Professor of Anatomy, Gadag Institute of Medical Sciences, Gadag, Karnataka,India, ${ }^{3}$ Dr. Sameen Taz, Assistant \\ Professors, Department of Anatomy, Sri Devaraj Urs Medical College, Kolar, Karnataka, India, ${ }^{4}$ Dr. Shaik Hussain Saheb, \\ Assistant Professor of Anatomy, JJM Medical College, Davangere, Karnataka, India.
}

Address for Correspondence: Dr. Shaik Hussain Saheb, Assistant Professor, Department of Anatomy, JJM Medical College, Davangere, Karnataka, India. Email: anatomyshs@gmail.com

\begin{abstract}
Background: The anterior division of the internal iliac artery usually gives origin to the uterine artery and vaginal artery in common. Uterine artery travels in cardinal ligament to reach uterus by crossing the ureter anteriorly \& parametrium of the inferior broad ligament of the uterus gives way for the uterine artery. Uterus is mainly supplying by uterine artery and it is anastomosing usually with ovarian artery. Vaginal artery is source of blood supply to vagina and lower part of urinary bladder. Objectives: The present study conducted to study the morphological features of uterine and vaginal arteries, and their variations, in origin and branching pattern. Materials and Methods: Dissection of 50 adult human pelvic halves was procured from embalmed cadavers of J.J.M. Medical College and S.S.I.M.S \& R.C, Davangere for the study. Results: Out of 50 specimens uterine and vaginal arteries we had traced only in 17 specimens. Out of these 17 specimens, uterine artery took origin from anterior division directly in 15 specimens and double uterine artery was observed in 2 specimens. Vaginal artery took origin from anterior division directly in 15 specimens and with internal pudendal artery in 2 specimens. Conclusion: Uterine and vaginal arteries in majority of cases taken origin from anterior division of internal iliac artery and in few cases vaginal artery taken origin from internal pudendal artery. The knowledge of uterine and vaginal arteries is very important during obstetrics and pelvic surgeries and in treating of diseases related female pelvic organs.
\end{abstract}

Key words: Uterine artery, vaginal artery, Uterus, Internal iliac artery

\section{Introduction}

Arteries are essentially conducting channels through which blood is conveyed from the heart to the capillary bed. The blood vascular tree has at all times been a particularly interesting phase of anatomical study. Its influence on the development of the individual, its practical importance in medicine and the necessity for the surgeon to thoroughly orient himself with it, gives additional stimuli to further our knowledge concerning it. In general, arteries pursue the shortest and the most direct course in order to reach their objective and that this course is partly determined by mechanical convenience.

The angle at which branches leave a main arterial stem certainly depends to a considerable extent on haemodynamic factors [1]. The distribution of the branches of a main artery is determined by functional considerations as the result of which structures taking part in a common activity tend to be vascularised by branches

Manuscript Received: $20^{\text {th }}$ May 2017

Reviewed: $30^{\text {th }}$ May 2017

Author Corrected: $8^{\text {th }}$ June 2017

Accepted for Publication: $15^{\text {th }}$ June 2017 of the same arterial stem, functionally connected structures inevitably make simultaneous demands on the circulation and it may therefore be a matter of convenience that they should be supplied from the same source $[2,3]$.

The internal iliac artery anterior division is main source for origin of uterine artery along with vesicle arteries, rectal artery, internal pudendal artery, sciatica. According to recent angiographic studies uterine artery showed variations in its origin. Based on the origin source it is classified as different types. Type I is the origin of the uterine artery inferior gluteal artery ram, type II is the origin of the uterine artery bifurcation ram inferior gluteal artery $6 \%$, type III is the origin uterine artery to the internal iliac artery of the ram trifurcation, with the upper and lower gluteal artery, type IV is proximal to the origin of the uterine artery to the origin of the upper and lower gluteal arteries. Recent studies, which are based on angiographic examination, note the presence of two trunks 


\section{Original Research Article}

of bifurcation of the internal iliac artery anterior and posterior, and uterine artery is inferior gluteal artery origin or branch of the internal iliac artery trifurcation. The vaginal artery is a branch of the anterior division of the internal iliac artery. It is often considered to be a homolog of the inferior vesical artery, which is present only in males.

The vaginal artery gives vaginal and inferior vesical branches. Vaginal branch descends to the vagina, supplies it and can anastomose with the vaginal branch of the uterine artery. Inferior vesical branch proceeds towards the fundus of the bladder.

The vaginal artery supplies the lower portion of the vagina, the vestibular bulb, rectum and the fundus of the bladder. The upper part of the vagina is supplied by the uterine artery. The knowledge of uterine and vaginal arteries are very helpful in surgeries of uterus $[4,5,6,7]$.

\section{Materials and Methods}

Study design- Present study designed to study morphological features of uterine and vaginal arteries in human dissected pelvis.

Settings- 50 formalin fixed adult human pelvic halves were procured from the Department of Anatomy, J.J.M. Medical College and S.S. Institute of Medical Sciences and Research Centre, Davangere.
Inclusion criteria- well dissected pelvic sections during routine undergraduate dissection, the specimens with well-preserved vascular pattern.

Exclusion criteria- specimens not properly dissected, spoiled pelvic sections, pelvic sections without or not well preserved vascular pattern.

Methodology- A horizontal section through the abdomen at the fourth lumbar vertebral level was taken. The pelvic specimen thus obtained was divided into two equal halves by cutting through the pubic symphysis, the sacrum and coccyx. This section divided the bladder, (uterus and vagina in female) and rectum longitudinally. Then, the peritoneum was removed from the bladder, uterus (in female), rectum and the lateral pelvic wall of each half of the pelvis. The level of origin of internal iliac artery was noted, the length of the trunk of the vessel was measured.

The level of its termination into anterior and posterior division was identified and noted. Uterine and vaginal arteries were studied for their variations and course. The specimens were numbered and photographs of each specimen were taken by digital camera and the arterial tree was coloured red digitally and labelled. The specimens were preserved by using $5 \%$ formalin solution.

Statistical analysis- we have calculated simple percentage of uterine and vaginal artery out of total number of specimens.

\section{Results}

Out of 17 specimens, uterine artery took origin from anterior division directly in 15 specimens (88\%) and double uterine artery was observed in 2 specimens (12\%) (Figure 1). Out of 17 specimens, vaginal artery took origin from anterior division directly is 15 specimens $(88 \%)$ and with internal pudendal artery in 2 specimens $(12 \%)$ (Table no 1,2$)$.

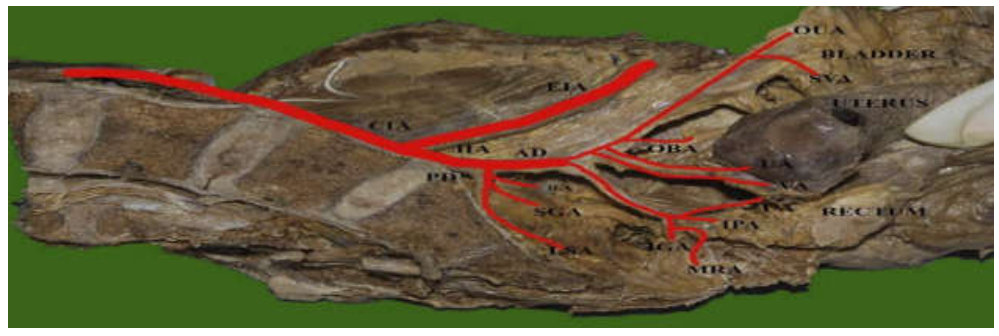

Figure-1: Uterine artery taking origin from internal pudendal artery

Table No.-1: Origin of uterine artery as observed in 17 specimens.

\begin{tabular}{|c|c|c|c|}
\hline Division & Origin & Specimen & Percentage \\
\hline $\mathrm{AD}$ & $+/ \mathrm{N}$ & 15 & 88 \\
\hline & Double & 2 & 12 \\
\hline & Total & 17 & 100 \\
\hline
\end{tabular}

Table No.-2: Origin of vaginal artery as observed in 17 specimens. 
Original Research Article

\begin{tabular}{|c|c|c|c|}
\hline Division & Origin & Specimen & Percentage \\
\hline $\mathrm{AD}$ & $+/ \mathrm{N}$ & 15 & 88 \\
\hline & With IPA & 2 & 12 \\
\hline & Total & 17 & 100 \\
\hline
\end{tabular}

AD: Anterior division, IPA: internal pudendal artery.

\section{Discussion}

The blood vascular tree has at all times been a particularly interesting phase of anatomical study. The establishment of anatomic types aims to generalize the variations of the large arterial trunks of the body, to arrange them into a form more easily comprehended and retained. In anatomic terms, the uterine artery runs down the retroperitoneal space of the lateral pelvic wall, travels intraperitoneally through the broad ligament, and then gives off ascending branches to the uterine body and descending branches to the cervix uteri at the uterine margin. In terms of embryology, the uterine artery develops as a branch of the anterior division of the internal iliac artery, which in itself develops from the patent part of the umbilical artery.

The origin of the uterine artery in human fetuses in most cases arises separately from the internal iliac artery. Side branches of the uterine artery mainly supply the vagina, the ovaries, the Fallopian tubes they have variable development and in this respect are visible on angiography with varying frequency [5]. Other anatomic variations of the uterine artery are rare. The uterine artery may have a common trunk with another branch of the internal iliac artery, for example, with the vesical, the vaginal, or the internal pudendal arteries $[5,8]$.

Saraiya et al. reported the replacement of the uterine artery by the round ligament artery [9]. Pelage et al. stated that the uterine artery may be replaced by multiple small artery branches and presented a flush pelvic aortogram as an example of this [8]. The same observation, with only multiple small branches lacking a distinct uterine artery trunk on either side, was made during a uterine artery embolization by Worthington-Kirsch et al [10], who for that reason had to abandon the procedure. The supposed existence of the duplication of the uterine artery has been reported by several authors; however, in most cases this has only been in the form of secondary literature [5,11]. In researching the primary literature, we were not able to

find a single case of a duplicated uterine artery proven on angiography, because, as mentioned above, variants seem to occur as the absence of a uterine main trunk with replacement of the uterine artery by multiple small vessels originating from the internal iliac artery supplying the uterus [9]. We only came across one reported case of a duplicated uterine artery, discovered and photographed during a laparoscopic hysterectomy [12].

Anatomic variants of the uterine artery are rare, with the absence of one of the uterine arteries presumably being the most abundant variant. A duplicated uterine artery is mentioned in the medical literature. A partially duplicated uterine artery is an extremely rare variant not previously mentioned in the literature, and it could lead to technical difficulties or cause problems in various gynecological interventions. In the present study, out of 17 specimens, uterine artery took origin from anterior division directly in 15 specimens $(88 \%)$ and double uterine artery was found in 2 specimens $(12 \%)$. This correlate with the observations of Bergman [13] in which, the uterine artery usually arises from the internal iliac artery. The artery may be doubled or composed of multiple parts. In the present study, out of 17 specimens, vaginal artery took origin directly from anterior division in 15 specimens $(88 \%)$, with internal pudendal artery in 2 specimens $(12 \%)$. Bergman [13] states that, vaginal artery usually arises from the uterine artery, sometimes as several branches, and sometimes from the internal iliac in common with the uterine artery. The vaginal artery may also arise from the middle rectal or superior vesical artery. A duplicated uterine artery is an extremely rare anatomic variant. Knowledge of this variant is important, especially for the gynaecologist performing minimally invasive surgical procedures.

Conflict of interest: None declared.

\section{Funding: Nil, Permission from IRB: Yes}

\section{References}

1. Clark WEL. The tissues of the body. $5^{\text {th }}$ ed., Oxford- Clarendon Press; 1965.p.190-97.

2. Lipschutz B. A composite study of the hypogastric artery and its branches.Ann Surg 1918; 67 (5): 584-608.

3. Havaldar PP, Taz S, Angadi AV, Saheb SH. Morphological study of obturator artery. Int J Anat Res. 2014; 2(2):354-7.

4. Gomez-Jorge J, Keyoung A, Levy EB, Spies JB. Uterine artery anatomy relevant to uterine leiomyomata 


\section{Original Research Article}

embolization. Cardiovasc Intervent Radiol. 2003 NovDec; 26(6):522-7.

5. Pelage JP, Le Dref O, Soyer P, et al. Arterial anatomy of the female genital tract: variations and relevance to transcatheter embolization of the uterus. AJR Am J Roentgenol. 1999; 172: 989-994. 10.2214/ajr.172.4. 10587133.

6. Havaldar PP, Taz S, Angadi AV, Saheb SH. Study of posterior division of internal iliac artery. Int J Anat Res. 2014;2(2):375-9.

7. Pavan P Havaldar et al. Study of medial circumflex artery Int J Anat Res.2014;Vol 2(2):380-82.

8. Pelage JP, Le Dref O, Soyer P, Jacob D, Kardache M, Dahan H, Lassau JP, Rymer R. Arterial anatomy of the

female genital tract: variations and relevance to transcatheter embolization of the uterus. AJR Am J Roentgenol. 1999 Apr;172(4):989-94.

9. Saraiya PV, Chang TC, Pelage JP, Spies JB. Uterine artery replacement by the round ligament artery: an anatomic variant discovered during uterine artery embolization for leiomyomata. J Vasc Interv Radiol. 2002; 13(9):939-41.

10. Worthington-Kirsch L, Walker WJ, Adler L, Hutchins FL. Anatomic variation in the uterine arteries: a cause of failure of uterine artery embolisation for the management of symptomatic myomata. Min Invas Ther Allied Technol. 1999;8(6):397-402.

11. Spies JB. The pitfalls of uterine embolization: avoiding the failed procedure. In: Spies JB, Pelage JP, editors. Uterine artery embolization and gynecologic embolotherapy. Philadelphia: Lippincott Williams \& Wilkins; 2005. p. 95-105.

12. Lee KH, Park TC, Park JS. Duplicated uterine arteries in laparoscopic hysterectomy. J Minim Invasive Gynecol. 2008 Jan-Feb;15(1):3. doi: 10.1016/j.jmig.2007.05.006.

13. Bergman RA, Thompson SA, Afifi AK and Saadeh FA.mCompendium of human anatomic variation.Baltimore and Munich: Urban and Schwazenberg;1988.p.84-85.

\section{How to cite this article?}

Nataraj KM, Pavan P Havaldar, Sameen Taz, Shaik Hussain Saheb. A study on uterine and vaginal arteries and their clinical significance.Int J surg Orthopedics. 2017; 3(2):29-32.doi:10.17511/ijoso.2017.i02.01. 